\title{
Research on Location Selection of Rail Transit Park and Ride based on Capacity
}

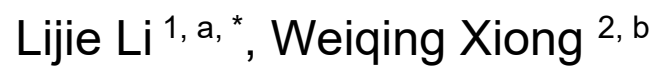 \\ 1. Ningbo City College of Vocational Technology, Ningbo, China \\ 2. Ningbo University, Ningbo, China \\ a, ${ }^{*}$ lilijie@nbcc.edu.cn, ${ }^{b}$ xiongweiqing@nbu.edu.cn
}

\begin{abstract}
Taking the capacity of parking and transferring facilities as the starting point, this paper focuses on the capacity calculation of parking and transferring facilities and capacity-based parking and transferring location selection in rail transit. On this basis from the perspective of parking and transfer facilities capacity, combined with the basic theory of value utility, attraction range and nuclear density estimation, a capacity-based parking-and-transfer facilities demand forecasting model and a capacity-based greedy location model are constructed. Taking Ningbo City as a case city, the capacity of parking and transfer facilities along Ningbo Rail Transit Line 1 is quantitatively calculated.
\end{abstract}

Keywords: Location Selection; Park and Ride; Capacity.

\section{Introduction}

Under the background of the lack of relevant overall urban planning and effective guidance for construction, the blind and lack of unified planning of urban construction in the rapid urbanization development wave of my country has led to the contradiction between the spatial structure of urban land use and the urban transportation system that is increasingly demanding. And showing a growing trend. Most cities adopt the multi-center and multi-cluster model to deal with the pressure caused by the over-concentration of functions and high population density in the city center. The multi-center and multi-cluster model relies on large-capacity rapid public transportation, such as rail transit. But this is obviously in conflict with the current surge in private transportation, especially private cars. According to investigation and research, the public transportation sharing rate of Western Europe, Japan and other countries is much higher than that of our country, and the highest sharing rate of my country's megacities is only $20 \%[1]$. The small amount of single transportation and the personaloriented characteristics are the characteristics of private transportation. Low-density and decentralized development cities are more suitable for the development of private transportation, such as the United States. my country's population base is huge and land resources are very scarce. This typical high-intensity transportation demand is obviously not compatible with the development of scattered low-density land with developed private transportation. It will only aggravate the further unbearable urban transportation and make the already poor Urban traffic has worsened[2]. As the economy continues to develop and land prices continue to rise, more and more people choose to live in the surrounding and suburban areas. However, the excessive concentration of employment land in the city center leads to a large number of tidal commute traffic every day, which intensifies traffic congestion in the city[3].

Rail transit usually refers to a transportation system that uses a specific track to carry out passenger transport on a fixed route, among which subways and light rails are typical representatives of rail transit. According to the service range distance, it can be divided into intercity rail transit and urban rail transit. The object of this study is urban rail transit. It has far-reaching significance for the realization of sustainable urban development. It will greatly influence and change the overall situation and development mode of the city. The urgent task of developing a good ecological environment for cities is to transform the urban development model from a pie-type to a radial-type[4] . However, it is undeniable that while rail transit plays a positive role in avoiding the influx of a large number of cars into the city center and alleviating traffic congestion, there are also certain problems: some cities 
have fewer subway passengers, which makes the use of rail transit resources. Failure to maximize it will affect the profitability of rail transit and hinder the sustainable construction and development of rail transit itself. Therefore, the site selection of $P \& R$ park-and-ride facilities based on rail transit has very important practical significance.

The traditional facility location problem can be traced back to the median problem in Euclidean space proposed by scholars such as Fermat. It is a typical NP problem and a key problem in modern management operations research[5]. There are four types of public service facilities site selection issues. The location of public service facilities based on the coverage model is further refined into two types: the location of public service facilities based on progressive coverage and the location of public service facilities based on standby coverage; the location of public service facilities based on the hierarchical model includes The location problem of public service facilities based on the nonnested hierarchical model and the location problem of public service facilities based on the nested hierarchical model; the location problem of public service facilities based on competition is divided into the location problem of public service facilities based on the gravity model and The location problem of public service facilities based on market expansion; the location problem of public service facilities based on uncertain conditions can be divided into the location problem of public service facilities based on stochastic optimization and the location problem of public service facilities based on robust optimization. The location of facilities in transportation planning generally includes the location of rail transit stations, the location of bus stations, and the location of logistics turnover centers. The goal of location selection is usually to maximize demand coverage [6].

Traffic travel is one of the most common daily behaviors of urban residents, and the study of travel modes has expanded from aggregate methods to non-aggregate methods. The most typical method in the aggregate method is the four-stage forecasting method. The four-stage forecasting method is based on the residents' travel survey and goes through the four basic stages of attracting traffic volume, distributing traffic volume, traffic mode division, and traffic volume distribution[7]. The aggregate method is based on the travel population area as the basic unit, and the model is established based on the aggregate data of the divided areas. The aggregate method is convenient for modeling, simple for calculation, and highly maneuverable, but it cannot reflect the increasingly diverse trend of traffic demand, making the research results lose objectivity. Because of this, the non-aggregate method that directly takes each individual traveler as the research object came into being. There are many parkand-ride location theories based on the disaggregated method. This section will focus on the parkand-ride location model based on the optimal theory, the park-and-ride location model based on the probability theory, and the park-and-ride location model based on the interception location theory. The three typical location theories are illustrated by the location model.

\section{Parking and Ride Location Model based on Capacity}

Park-and-ride location selection is based on basic elements such as regional travel volume and transfer demand, using a variety of control and selection theories to determine a type of optimization problem for transfer parking locations[8]. Whether the park-and-ride site selection is reasonable or not is the fundamental determinant of the later benefits and effects of park-and-ride facilities. On the basis of meeting the needs of regional transfers, reasonable park-and-ride facilities will further induce more private car owners to transfer and increase the share rate of rail transit as a transportation mode[9]. Too little capacity of park-and-ride facilities can not really achieve the actual effect of the transfer, and too much capacity of park-and-ride facilities will result in idleness and waste of social resources.

This article starts with the goal of maximizing the benefits of traffic travellers. Based on the analysis of the influencing factors of park-and-ride demand, from the perspective of park-and-ride trip value and the range of attraction and intensity, the Logit model and kernel density function of the disaggregated model are used. Based on the theory of estimation and greedy algorithms, it 
Volume 17 (2022)

incorporates the capacity of park-and-ride facilities to construct a capacity-based park-and-ride location model for rail transit.

\subsection{Factors Affecting Park and Ride Demand}

The delay in transfers involves a wide range of factors. It is generally believed that the time it takes to find parking spaces for private car travel and the time from parking and transfer facilities to rail transit stations is generally believed. The proportion of time spent in private car travel to find parking spaces in the delay in the entire transfer is a key factor in deciding whether to park and ride. The lower the proportion, the more it can attract a large number of private car owners through park-andride mode. Arrived at the destination. The increase in the proportion shows that the time spent on finding parking spaces in the middle of the transfer is rising, which reduces the comfort of parking and transfer for private car owners, and the experience becomes worse. The time from the park-andride facility to the rail transit station reflects the distance from the park-and-ride facility to the station. The longer the time, the longer the distance from the park-and-ride facility to the station. According to an incomplete survey, for every $5 \%$ reduction in the time spent from park-and-ride facilities to stations, the number of people who park-and-ride increases by about $10 \%$. An important factor in the location of the facilities.

The economic cost of park-and-ride generally includes energy costs, parking costs, and other costs.Energy costs in the park-and-ride method are reflected in rail transit ticket prices and private car fuel costs. For the same starting and ending sections, rail transit fares are much cheaper than private car fuel costs.

$$
\begin{gathered}
f_{c}=6.372-0.716 r_{g}+0.138 v-0.001 v^{2} \\
p_{o-d}=k l_{o-d}\left(1 / f_{c}\right)
\end{gathered}
$$

In formulas (1) and (2), is the fuel consumption, the unit is. Indicates the condition of the road surface. The value is 1 for cement roads and 0 for asphalt roads. Is the average speed, and the unit is. Indicates the direct fuel consumption cost between the starting point and the ending point, and the unit is yuan. It is the unit price of gasoline in yuan/liter. Is the distance between the start point and the end point.

The price of parking fees incurred during the park-and-ride process varies greatly. Parking fees in the city center are generally higher due to various factors such as land prices, while those in the outer suburbs are relatively cheap. Other costs in park-and-ride usually refer to additional costs incurred by vehicle loss and traffic accidents.

\subsection{The Scope of Impact of Park and Ride Demand}

The scope of impact of park-and-ride facilities refers to the geographical distribution area of travellers affected by the transfer. The calibration of the scope of impact of park and ride facilities is a part of the entire demand forecast, which is also a basis for the investigation and analysis of the travel characteristics of travelers in the region. At present, the method of calibrating the scope of influence is generally divided into two types: geometric form and travel cost of various travel modes.

According to the geometric research of the influence area, the geometric form of the influence area of the park and ride facility generally presents a parabolic or circular shape, and the parabolic form of the influence area accounts for the vast majority. The range of influence of the parabolic geometry is based on an assumption: the majority of park-and-ride riders move toward the park-and-ride facility in the same direction as their destination, and only a small number of travelers move toward the parkand-ride facility. The direction is the opposite of the direction of travel to the destination. The influence range of the calculation of the parabolic geometry is to set the park-and-ride facility as the focus of the parabola, and the maximum distance to the park-and-ride facility obtained by the survey statistical method is obtained through the mathematical theory of the parabolic equation and the 
knowledge of the parabolic curve. A closed parabola, which is the range of influence of the park and ride facility to be solved.

According to the foregoing, the influence range of the park-and-ride facility presents a closed parabolic curve, and the area covered by the curve is mainly divided into two parts. Among them, the main demand, which accounts for about $85 \%$ of the total demand ratio, comes from the parabolic range within 16.1 kilometers of the park-and-ride facility's forward direction to the park-and-ride facility and the forward direction to the destination. The demand for park and ride in a circle with a radius of 5 kilometers from the center of the park and ride facility is about $50 \%$, as shown in Figure 1 .

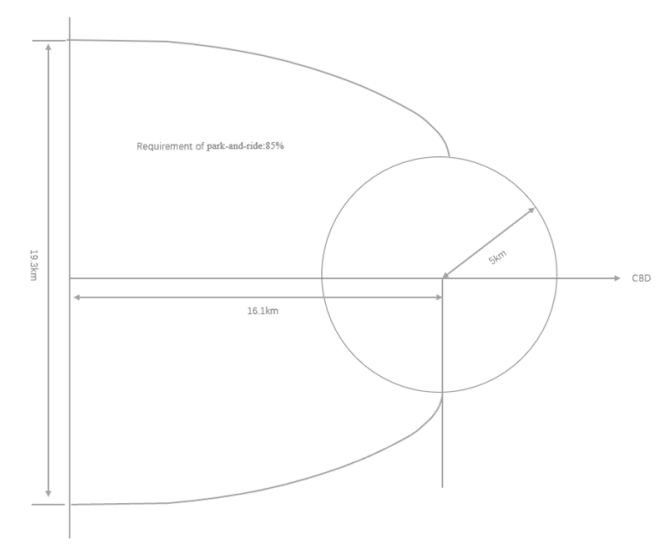

Figure 1. The attraction range curve of park and ride facilities

The method of calibrating the scope of influence based on travel cost comparison is to compare the cost of using a private car to reach the destination directly with the travel cost of transferring through public transportation such as rail transit to determine the scope of influence. By comparison, it is assumed that the area of the user whose cost of driving directly to the destination is higher than the cost of the transfer method is the area of influence of the park-and-ride facility.

\subsection{Park-and-ride Attraction}

In order to quantify the willingness of travelers to transfer trips, the concept of attraction strength of park-and-ride facilities is introduced. Generally speaking, the willingness to park-and-ride is inversely proportional to the distance from the point of travel to the park-and-ride facility. Travelers who are farther from the park-and-ride facility are less willing to use park-and-ride travel. In this paper, a function is used to express the attraction strength of the park and ride facility, and in the form it is expressed by non-parametric estimation, namely kernel density estimation, as shown in formula (3). In formula (3), $\mathrm{K}$ is the kernel function, and $\mathrm{h}$ is the width of the window.

$$
f_{x}=\frac{1}{n} \sum_{j=1} K\left(\frac{x-x_{i}}{h}\right)
$$

Kernel density estimation is commonly used in probability statistics to estimate unknown density functions. It is one of the non-parametric testing methods and is also known as Parzen window. When using kernel density estimation to estimate the boundary area, attention should be paid to boundary effects. When using the kernel density method to estimate unknown density, the focus is on the choice of kernel function type and the choice of window width. According to the practical effect of kernel density estimation, the first thing is to ensure that the density distribution of the kernel function is basically consistent with the fitted data distribution as much as possible, and on this basis, adjust the width of the window to achieve the best degree of data fitting. Commonly used kernel functions include uniform kernel, triangular kernel, Gaussian kernel and cosine kernel, and the corresponding kernel function graphs are shown. The kernel function of the uniform kernel is displayed horizontally, 
as shown in A in Figure 2. The trigonometric chord function presents a triangle, as shown in B in Figure 2. The Gaussian nucleus is hat-shaped, as shown in $\mathrm{C}$ in Figure 2, and the cosine nucleus has a vertical parabolic shape, as shown in D in Figure 2.

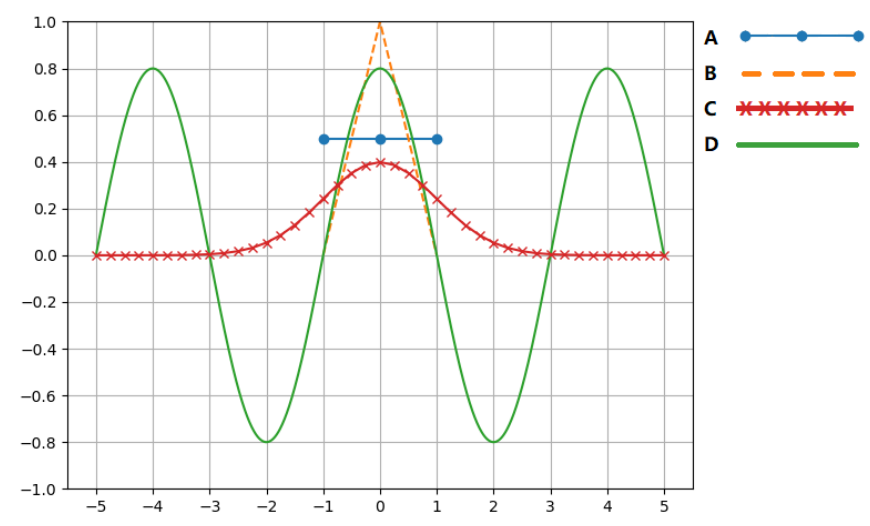

Figure 2. Kernel function

According to the matching degree between the image shape of the kernel function and the parking and transfer attraction range image, this paper chooses the cosine kernel as the kernel of the kernel density estimation. The cosine kernel expression is formula (4)

$$
K(x)=A \cos (\alpha x)
$$

Among them, A and $\alpha$ are undetermined constants, when $A=\pi / 4$ and $\alpha=\pi / 2$ are commonly used cosine kernel functions. Since the optimal window band value of the cosine kernel function cannot be directly obtained under conventional numerical calculation methods, this paper constructs an iterative algorithm to obtain the optimal window width value corresponding to the cosine kernel function, and the optimal window width is expressed by formula (5)

$$
h_{o p t}=\left\{\frac{\left(\alpha^{6}+\alpha^{5} \sin \alpha \cos \alpha\right) /\left(4\left(\alpha^{2} \sin \alpha+2 \alpha \cos \alpha-2 \sin \alpha\right)^{2}\right)}{\frac{1}{n h^{6}}\left\{2 \sum_{i=1}^{n} \sum_{j<i}^{n}\left[r_{i j}\right]+\sum_{i=1}^{n}\left[r_{i}\right]\right\}}\right.
$$

The window value calculated by the iterative algorithm is the optimal window width. Although it is difficult to obtain the specific form of the window width in the actual calculation process, it can be assumed to obey the normal distribution as a whole, and then the optimal value $1.60 \sigma n^{-1 / 5} \mathrm{can}$ be calculated. At the beginning of iterative calculation, the general value is $1.06 \sigma n^{-1 / 5}$.

During the research process, for 1500 randomly generated sample objects that conform to the normal distribution, the plots show different cosine kernel functions by adjusting different values. Furthermore, the fitted cosine kernel function is compared and analyzed with the actual probability density function curve. When the value is set to $1 / 6$, the fitted probability density distribution curve has the highest degree of adaptation to the actual probability density distribution function curve.

\subsection{Parking and Ride Location Algorithm based on Capacity}

The process of the capacity-based park-and-ride location model is as follows: take the rail transit station list as the location of the alternative park-and-ride facilities, calculate the attraction range of each station, and the amount of car trips within the range is used as the park-and-ride demand Based on the attraction strength as the travel possibility, combined with the distance from the candidate station to the city center, the following model can be used to obtain the best park-and-ride location. 


$$
\begin{aligned}
& w(z)=\sum_{r} \sum_{i} q_{r i} d_{r i} x_{r i} \\
& \text { s.t. } \sum_{r}^{n} \sum_{i=1}^{m} x_{n} \leq P, \forall r, i \\
& \sum_{i=1}^{m} x_{r i} \geq 1, \forall r \\
& x_{n} \in\{0,1\}, \forall r, i \\
& \left|d_{r i}-d_{g j}\right| \geq D, r=g, i \neq j
\end{aligned}
$$

This paper uses the greedy algorithm in the optimization algorithm to solve the formula (6). The core idea of the solution process is the local optimization. In this iterative operation process, only the optimal solution is selected for the next round of iterative calculations, focusing only on Maximize current benefits. In formula (6), a complete greedy algorithm process is to select the rail transit station that maximizes the objective function, and select an optimal one each time. When the number of parkand-ride facilities to be selected is more than one, it is only necessary to continue the calculation of the greedy algorithm in the list of remaining alternative park-and-ride facilities.

\section{Experiments}

At present, Ningbo City does not have a standard park-and-ride system, so the transfer model of the park-and-ride probability of Ningbo Rail Line 1 is mainly based on SP survey data refined according to the influencing factors of demand forecast proposed in Chapter 2. In this paper, we only calculate the park-and-ride demand for two modes of direct access by private cars and rail-based parkand-ride trips.

Table 1. Attraction strength

\begin{tabular}{|c|c|}
\hline site & Park-and-ride capacity demand (units) \\
\hline Takahashi West & 108 \\
\hline Liangzhu Station & 56 \\
\hline Xujiacao Changle & 140 \\
\hline Wangchunqiao Station & 352 \\
\hline Daqing Bridge & 382 \\
\hline Sakura Park Station & 219 \\
\hline Fuming Road & 183 \\
\hline Bao Zhuang & 25 \\
\hline Daqi & 376 \\
\hline Changjiang Road & 459 \\
\hline
\end{tabular}

Table 2. Park-and-ride capacity based on attraction strength

\begin{tabular}{|c|c|}
\hline site & Attraction strength (percentage) \\
\hline Takahashi West & 11.3 \\
\hline Liangzhu Station & 4.5 \\
\hline Xujiacao Changle & 7.2 \\
\hline Wangchunqiao Station & 13.7 \\
\hline Daqing Bridge & 12.8 \\
\hline Sakura Park Station & 8.6 \\
\hline Fuming Road & 9.3 \\
\hline Bao Zhuang & 5.9 \\
\hline Daqi & 12.6 \\
\hline Changjiang Road & 14.1 \\
\hline
\end{tabular}

In order to calculate the attraction range of each station, this paper uses the least square method to fit the parabolic curve according to the park and ride questionnaire conducted by each station, and uses the park and ride parabola attraction range proposed in Chapter 2 to define. Taking the Gaoqiao West Park and Ride Station as an example, the distance between the start point of the park and ride 
respondent and the park and ride point is fitted according to the parabolic model, and $85 \%$ of the park and ride the attractive range of travelers is within a parabolic range of 8.5 kilometers away from the parking and transfer point of Gaoqiao West Station. With the same treatment, the attraction range of other stops on Line 1 can be obtained.

Using the formula for calculating the attraction strength within the attraction range, according to the cosine kernel density function constructed in the text, the attraction strength of each stop and transfer point along the route of Line 1 is calculated, and the result is calculated See Table 1 for the attractive strength of.

\section{Summary}

This paper systematically learns the theory of park-and-ride facility location, and divides it into the theory of park-and-ride location based on optimal theory, the theory of park-and-ride location based on probability theory, and the theory of park-and-ride location based on interception theory. There are three types of site theory, and a summary comparative analysis is carried out. There are two main innovations in this research: First, the capacity is introduced into the study of the location of park and ride facilities, and all the entry points of capacity are transformed into a complex problem of the site selection of rail transit facilities into a capacity-constrained public service facility The location problem provides a new way of location decision-making for the location of rail transit park and ride facilities, and also provides research ideas and methods for the location of other public service facilities; second, it replaces the layout optimization method based on qualitative analysis , Applying the theory of attraction intensity and nuclear density estimation to capacity measurement provides a theoretical basis for the quantitative and accurate calculation of park and ride facility capacity.

\section{References}

[1] Bibhuti Sharma, Mark Hickman, Neema Nassir. Park-and-ride lot choice model using random utility maximization and random regret minimization[J], 2019(1):217-232.

[2] Khaled Shaaban, Hatem Abou-Senna, Dina Elnashar, Essam Radwan. Assessing the impact of converting roundabouts to traffic signals on vehicle emissions along an urban arterial corridor in Qatar[J]. Journal of the Air \& Waste Management Association,2019 (2):178-191.

[3] Xiaopeng Shen, Feng Chen, Baojian Su. Optimization of park-and-ride system: A case study of Shunyi in Beijing [J]. Advances in Mechanical Engineering, 2017:1-8.

[4] Bíl, M., Andrášik, R., Sedoník, J. A detailed spatiotemporal analysis of traffic crash hotspots[J]. Applied Geography 2019: 82-90.

[5] Heigl, F., Horvath, K., Laaha, G., Zaller, J. G. Amphibian and reptile road-kills on tertiary roads in relation to landscape structure: using a citizen science approach with open-access land cover data. BMC Ecology, 2017: 17-21.

[6] Thanh Mai Pham Ngoc. Adaptive optimal kernel density estimation for directional data[J]. Journal of Multivariate Analysis Volume 173, September 2019:248-267.

[7] De Tina Annemaria, Chau Anthony, Carusi Daniela A, Robinson Julian N, Tsen Lawrence C, Farber Michaela K. Identifying barriers to implementation of the national partnership for maternal safety obstetric hemorrhage bundle at a tertiary center: utilization of the delphi method. [J]. Anesthesia and analgesia, 2019:124-133.

[8] Pei Jingjing, Liu Wen, Han Lu. Research on evaluation index system of Chinese city safety resilience based on delphi method and cloud model. [J]. International journal of environmental research and public health, 2019:1-16.

[9] Humphrey-Murto Susan, Wood Timothy J, Gonsalves Carol, Mascioli Kelly, Varpio Lara. The delphi method. [J]. Academic medicine: journal of the Association of American Medical Colleges,2019:85-89. 